\title{
Successfully Embedding Mental Health Literacy into Canadian Classroom Curriculum by Building on Existing Educator Competencies and School Structures: The Mental Health and High School Curriculum Guide for Secondary Schools in Nova Scotia
}

\author{
Yifeng Wei, Stan Kutcher, Heather Hines, Amy MacKay \\ Research Associate, Sun Life Financial Chair in Adolescent Mental Health Team
}

\begin{abstract}
The necessity for development of mental health literacy in youth is gaining global attention with various approaches being considered worldwide. Our team in the province of Nova Scotia, Canada, has addressed this need through school curriculum embedded within usual grade nine-classroom education taught by usual, albeit trained, teachers using the Mental Health and High School Curriculum Guide. In this study, we evaluated the impact on the mental health literacy of 228 teachers who were learning how to implement the Guide in their classrooms by participating in a one-day training session, using a paired samples $t$ test and Cohen's effect size (d). The analysis demonstrated significant $(p=0.001)$ and substantial $(d=i .85$ and $d=0.5)$ improvements in both domains. These results are consistent with and replicate a previous study on the Guide demonstrating that an approach directed toward assisting teachers in their use of an educational resource may be a viable and easily implemented option for jurisdictions that are looking to improve mental health literacy in their schools.
\end{abstract}

\section{Introduction}

Globally, approximately one in five young people will experience a mental disorder before age 25 , with a substantial number developing recurring or chronic patterns of mental illness [1]. Thus, the adolescent years are a critical period for mental health promotion, prevention, early identification and effective treatment for mental disorders that may significantly improve both short and long term educational/vocational, social, interpersonal, health and family outcomes [2] [3]. Unfortunately, although a host of evidence-based treatments are available, many young people with a mental disorder are not identified and do not receive the treatment they need [4] [5]. This is due to many factors, including a lack of knowledge about mental health and mental disorders, stigma related to mental illness, and limited access to, or availability of, appropriate mental health care [6] [7]. Some of these barriers may be overcome in part with enhanced youth mental health literacy demonstrating that improvements of mental health knowledge and attitudes towards mental illness are related to enhanced help-seeking behaviors and/or help-seeking efficacy [5] [6] [8] [9].

Knowledge, attitudes and help-seeking behaviors are major components of mental health literacy, defined as the capacity to understand what constitutes positive mental health and learning about strategies to obtain and help maintain positive mental health; knowledge about mental disorders and their treatment based on best available evidence, improved attitudes towards those living with mental disorders (decreased stigma) and enhanced personal capacity to seek mental health care from appropriate health care providers should that be required [10].

The importance of mental health literacy for young people is widely recognized and various approaches purporting to address this issue have been promoted, with school based interventions considered to be a predominant venue in which this could be realized [11]. Crucial to the success of this approach is enhancing mental health literacy amongst teachers who will be addressing mental health literacy in their classrooms. Educators report that they consider mental health as extremely important for student outcomes and well-being, but do not feel that they have the knowledge to help students in this area [12]. Thus, mental health literacy training for teachers is needed in order to enhance their mental health competencies and support their implementation of mental health literacy within their classrooms. This has been nationally recognized in Evergreen, the Canadian child and youth mental health framework, and provincially in Nova Scotia in the policy document Kids and Learning First [13] [14].

Some approaches to addressing youth mental health literacy have used mental health experts, providing classroom interventions [15]. Others have applied stand-alone programs primarily targeted to the general public and directed at stigma reduction [16] [17]. Neither approach builds sustainable and system integrated capacity, nor 
does a stigma dominated focus easily enhance other important domains of mental health literacy, including knowledge and help-seeking efficacy. This may be better obtained through embedding mental health literacy into usual school curriculum taught by usual teachers [5] [9] [11] [13] [18]. The approach taken in the province of Nova Scotia (NS) is to embed mental health literacy into usual grade nine curriculum, where it is taught by teachers who have received training in how to apply a resource (the Mental Health \& High School Curriculum Guide) to achieve this goal. This approach builds on existing pedagogies, teachers professional competencies and current school structures and does not require additional, stand alone, noncontextualized interventions, that are costly and do not prepare teachers for their delivery of a mental health literacy curriculum. The Mental Health Curriculum Guide training utilizes teachers' existing professional competencies and prepares teachers in the manner that they usually use when learning new materials for classroom delivery. In an earlier study, this approach was evaluated in the Halifax Regional School Board (one of the school boards in NS) and found to be an effective tool for improving mental health knowledge and reducing mental illness stigma in teachers [10]. This paper reports the impact of the Mental Health \& High School Curriculum Guide (the Guide) on teachers' knowledge and attitudes as applied in all seven English school boards, across Nova Scotia.

\section{The Mental Health \& High School Curriculum Guide (the Guide)}

A mental health knowledge translation team, affiliated with Dalhousie University and the IWK Health Center, NS, created the Guide in collaboration with the Canadian Mental Health Association (national branch) to address mental health literacy for students. Subsequently, the Guide training program was designed, field-tested and modified by two of the authors to enhance mental health literacy for teachers and provide support for their application of the Guide in their classrooms. The first field-tests were conducted by these authors in collaboration with the English Program Services of the Nova Scotia Department of Education in three NS schools. These evaluations included assessment of the impact of the Guide training on teachers' mental health literacy and evaluated various methods of in class delivery conducted by the authors and independently by senior bureaucrats in the NS Department of Education [11]. As a result of the successful field-tests, the Guide and its training programs was integrated into the Nova Scotia policy/plan for education, Kids and Learning First [14].
This education policy/plan outlines the importance of implementing a comprehensive school mental health framework within the province through building mental health curriculum into health education and Healthy Living courses; providing mental health training to teachers and support staff; and providing mental health literacy for students and their families [14]. To help facilitate this policy/plan the Province collaborated with the team who created the Guide and its training programs to begin training educators and allied health professionals across the province in the use of the Guide. To date (March 2014), all teachers of Healthy Living (grade 9) in all English school boards have been trained and each school board has developed and trained board-based trainers who can inexpensively sustain the training of teachers using the Guide in their respective boards for years to come.

The Guide is made up of a teacher's self-study component and six classroom delivery modules, available in monograph and web-based formats. The six modules are designed to be taught in sequence so that students achieve mental health literacy through: an understanding of the basic functions of the brain in health and illness; details about different types of mental health problems and mental illnesses typically onsetting during the adolescent years and their best evidence supported treatments; a real-life introduction to young people's experiences of mental illness; strategies to fight stigma; how to access needed mental health care, enhancement of mental health self-care, competencies designed to improve the quality of care received and evidence based strategies and competencies that can be used to help obtain and maintain good mental health. It provides teacher ready core materials such as lesson plans, classroom activities, print and video resources, power-point presentations, evaluation options as well as a host of supplementary materials that can be used to enrich the student's educational experience. It has been successfully implemented in thousands of schools across Canada, and both cohort and RCT research studies have independently demonstrated significant and substantial positive impact in enhancing student mental health literacy: sustained improvements in knowledge, help-seeking efficacy and decreases in stigma [18] [19].

\section{Method and Analysis}

\subsection{Participants}

Over the course of eighteen months, one day training sessions were provided by two of the authors to teachers and trainers in all seven English school boards across Nova Scotia: 228 participants (56 males; 170 females), with 43 of those going on 
to receive a second one-half day enriched "Trainer" session. Trainers are sited in each school board and are expected to train new teachers annually who will be teaching the Healthy Living class in grade nine.

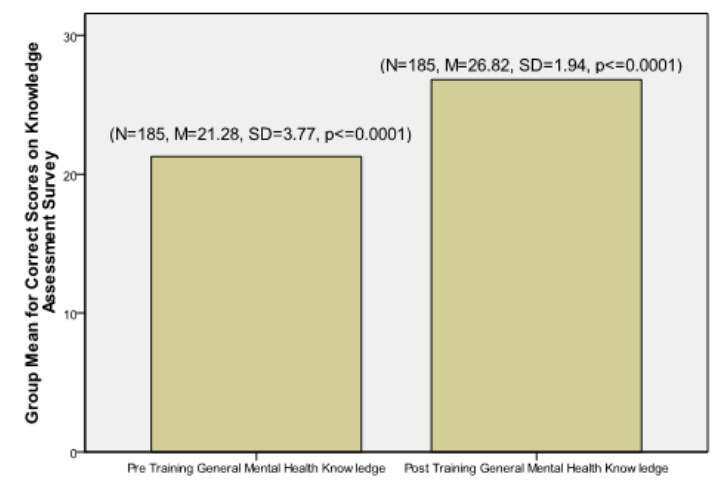

Figure 1. Group Mean for Educators' General Mental Health Knowledge

Training participants all taught Grade 9 Healthy Living, as well as other Junior High level classes such as Science, Math, Resource, Social Studies, French and English.

\subsection{Outcomes}

Pre and post evaluations of knowledge (see Figure 1) were available for 185 training program participants. Outcomes of the knowledge assessment survey reveal that prior to the training, as a group the educators correctly answered an average of $71 \%$ of the 30 general mental health questions $(\mathrm{M}=21.28$, Standard Deviation [SD] = 3.77 ) and their scores improved to $89 \%$ following participation in the training program $(M=26.82$, $\mathrm{SD}=1.94)$. This is a highly statistically significant change $t(184)=20.0, p<.0001 ; d=1.85$ (see Figure 1). The effect size for the educators' knowledge analysis substantially exceeded Cohen's convention for a large effect $(\mathrm{d}=1.85)$.

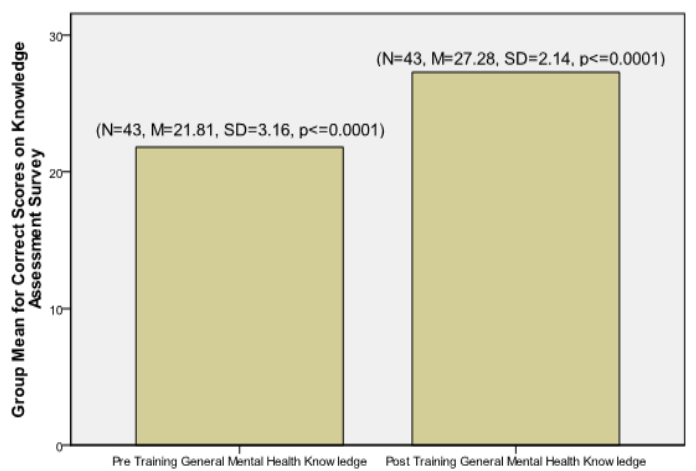

Figure 2. Group Mean for Trainers' General Mental Health Knowledge
Pre and post evaluations of knowledge (see Figure 2) were also available for 43 trainers. As a group, the trainers answered an average of $73 \%$ of the general mental health questions correctly in the pre-test $(\mathrm{M}=21.81, \mathrm{SD}=3.16)$ and their scores improved to $91 \%$ following the participation in the program

$(\mathrm{M}=27.28, \mathrm{SD}=2.14)$. This is a highly statistically significant change $t(42)=13.05, p=.0001 ; d=2.0$ (see Figure 2). The effect size for the trainer's knowledge analysis substantially exceeded Cohen's convention for a large effect $(\mathrm{d}=2.0)$.

A total of 178 educators completed the pre and post training portion of the survey that measures attitudes towards mental illness (see Figure 3). Educator attitudes were already highly positive at baseline. From a possible positive score of 56, educators' attitudes averaged $51.15(\mathrm{SD}=3.81)$ prior to training. Following training, educators' attitudes averaged $53.10(\mathrm{SD}=3.84)$. This change represented a statistically significant and substantial improvement in attitudes, $t$ (177) = 5.76, $p<=0.0001 ; d=0.51$, despite the initially highly positive attitudes score.

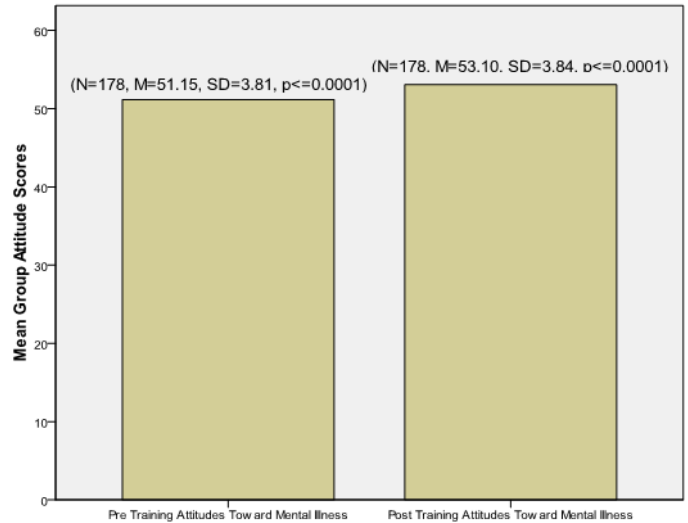

Figure 3. Group Mean for Educators Attitudes toward Mental Illness

A total of 39 trainers completed both the pre and post training evaluation portion of the attitudes assessment (see Figure 4). Trainers' attitudes were highly positive at baseline, averaging 51.15 out of 56. After the workshop, trainers' attitudes had improved and now averaged a score of 53.10 out of 56. This change represented a statistically significant improvement in attitudes, $t(38)=2.06$, $p<=0.046 ; d=0.53$ (see Figure 4). The effect size for trainers' attitudes were found to meet Cohen's convention for a medium effect $(\mathrm{d}=0.53)$.

Training participants also provided feedback regarding their satisfaction with the training. Using a six-point scale (i.e., $0=$ poor; $5=$ Excellent), 183 participants responded to all questions. When asked "Overall, I found the workshop useful and informative" participants' average score was 4.84 out of 5. In response to the question "Overall I 
found the speaker(s) to be of high quality" participants' average score was 4.92 out of 5 .

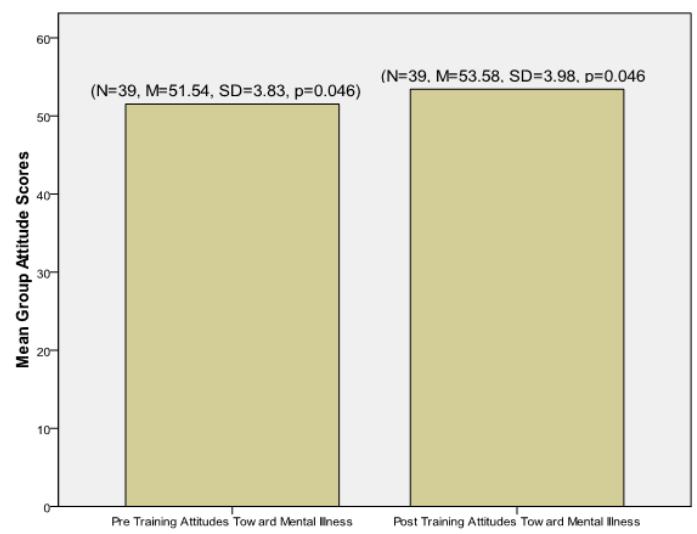

Figure 4. Group Mean for Trainers' Attitudes Toward Mental Illness

In response to the question "Overall I learned information and concepts that will be helpful to me in my work" participants' average score was 4.84 . When asked "would you recommend this workshop to your colleagues?" participants' average score was 4.88 . When asked to provide an overall rating for the workshop as participants' average score was 4.84 out of 5. Finally, participants were asked to rate this workshop compared to other similar workshops they have taken.

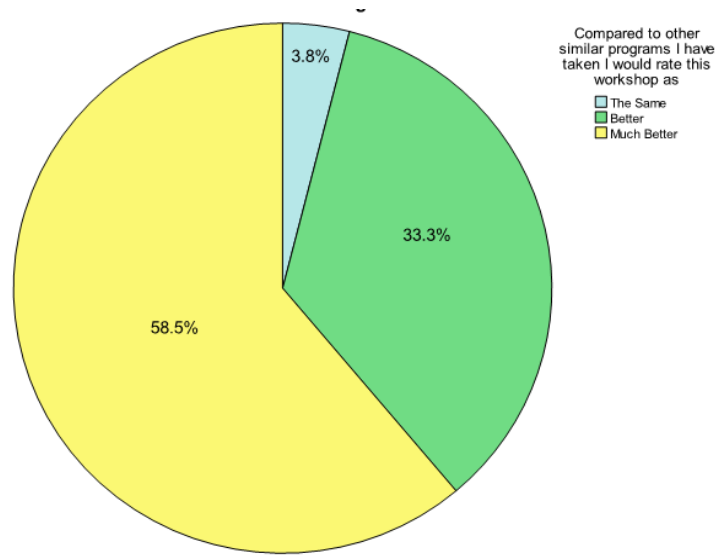

Figure 5. Mental Health Curriculum Guide Training Compared to Other Similar Programs

The options given were "Much Worse", "Worse", "The Same", "Better" and "Much Better." Participants rated the workshop as "The Same (3.8\%), "Better" (33.3\%) and "Much Better" $(58.5 \%)$. Eight participants did not answer this final question (4.4\%) (see Figure 5).

\section{Discussion}

Overall, this evaluation of the Guide teacher training delivered to 228 educators in all seven Nova Scotia English school boards indicates that the program significantly and substantially increased mental health knowledge and decreased negative attitudes and stigma associated with mental illness. The participants also scored their experience as very positive, as demonstrated in their high satisfaction ratings. These results demonstrate both the feasibility and positive impact of this novel approach toward enhancing teacher's mental health literacy. Not by providing noncontextualized stand alone mental health literacy programs but by building on existing pedagogic approaches that teachers use to help prepare them to teach curriculum in their classrooms, our results suggest that that such an approach may be widely applicable globally. Supporting this suggestion is further research conducted in various Canadian provinces, in different educational systems yielding closely similar results [10] [11] [20] [21] [22].

These findings, taken as a whole, indicate that the training on the Guide may be an effective tool for consideration in school boards that are looking to increase their mental health literacy among teachers and other educators.

Concurrently, although an economic analysis was not conducted as part of this evaluation, the cost of establishing and sustaining this curriculum embedded approach is low in practice. These include the cost of two training days for trainers in each school board and one day of teacher classroom release time to receive the training on use of the Guide. The latter can be achieved during already existing professional development days. The presence of a Guide training team in each board means that teachers new to the curriculum can be trained annually and the training team can be periodically replenished as circumstances warrant. All these strategies aim to reduce the cost while maintaining the quality of the Guide implementation.

In Canada, teachers are not exposed to mental health literacy during pre-service teacher training, however, in their everyday practice, they consider mental health as extremely important for students to achieve positive learning outcomes and report themselves as in substantial need for mental health literacy [9] [12]. Thus, training on the Guide may serve to bridge the gap between the pre-service teacher education and the realities of practice. The results reported in this evaluation provide a novel and promising approach to addressing the need to enhance mental health literacy in young people. A growing body of research is beginning to demonstrate the positive impact of school related approaches in increasing knowledge about mental health and mental disorders, decreasing stigma and 
enhancing help-seeking efficacy [10] [15]. Forthcoming reports will demonstrate the highly positive impacts in each of these domains that occur for students when teachers apply the Guide in classrooms [18] [19]. What separates this approach from others is the embedding of mental health literacy in usual school curriculum by enhancing existing teacher competences through dedicated resources (the Guide) and training in the use of these resources at relatively low cost. Thus, it helps normalize instead of sensationalize mental health/mental disorders and can be relatively easily sustained over time. Since this approach builds on existing teacher competencies and existing school structures, it avoids the challenges of stand alone programs that are parachuted into schools or that use extra-school resources [23].

The Guide also has the added advantage of being able to be globally applied, by utilizing an approach that is known to and familiar to education systems worldwide. For instance, a preliminary evaluation of this model in the African country of Malawi is reporting highly positive results [24].

\section{Conclusion}

Evaluation of the Mental Health Curriculum Guide training in the Province of Nova Scotia demonstrates that this approach significantly and substantially improves educators' mental health literacy and prepares them for the application of the Guide in usual school curriculum. This helps to set a strong foundation for the province of Nova Scotia to be able to effectively, efficiently and at minimal cost, enhance mental health literacy of young people, province-wide. This approach, building on teacher professional competencies, well established pedagogics (curriculum) and embedded into existing school structures may be a model for global dissemination as it builds on rather than adds to, school based process that are found world-wide. Further research evaluating this potential is currently underway.

\section{References}

[1] Kessler, R. C., Berglund, P., Demler, O., Jin, R., Merikangas, K. R., \& Walters, E. E. (2005). Lifetime prevalence and age-of-onset distributions of DSM-IV disorders in the National Comorbidity Survey Replication. Archives of General Psychiatry, 62(6), 593602 .

[2] Lancet Global Mental Health Group, Chisholm, D., Flisher, A. J., Lund, C., Patel, V., Saxena, S., Tomlinson, M. (2007). Scale up services for mental disorders: A call for action. Lancet, 370 (9594), 1241-1252.

[3] McGorry, P. D., Purcell, R., Goldstone, S., Amminger, P. (2011). Age of onset and timing of treatment for mental and substance use disorders:
Implications for preventative intervention strategies and models of care. Current Opinion in Psychiatry, 24, 301306.

[4] Waddell, C., Offord, D. R., Shepherd, C. A., Hua, J. M., \& McEwan, K. (2002). Child psychiatric epidemiology and Canadian public policy-making: The state of the science and the art of the possible. The Canadian Journal of Psychiatry / La Revue Canadienne De Psychiatrie, 47(9), 825-832.

[5] Kutcher, S. (2011). Facing the Challenge of Care for Child and Youth Mental Health in Canada: a critical commentary, five suggestions for change and a call to action. Health Quarterly, 14, 15-21.

[6] Jorm, A.F. (2012). Mental health literacy: Empowering the community to take action for better mental health. American Psychologist, 67(3), 231-43.

[7] Santor D., Short, K., \& Ferguson, B. (2009). Taking mental health to school: A policy-oriented paper on school-based mental health for Ontario. Prepared for the Provincial Center of Excellence for Child and Youth Mental Health at CHEO.

[8] Jorm AF, Korten AE, Jacomb PA et al (1997). Mental health literacy: a survey of the public's ability to recognise mental disorders and their beliefs about the effectiveness of treatment. Medical Journal of Australia 1997; 166, 182-186.

[9] Children's Mental Health Ontario. (2013). Building a better school environment for youth with mental health and addictions issues. Retrieved February 4, 2014 from http://www.kidsmentalhealth.ca/documents/res-buildinga-better-school-environment-for-youth-with-mentalhealth-and-addiction-issuesv2.pdf

[10] Kutcher, S., Wei, Y., McLuckie, A., \& Bullock, L. (2013). Educator Mental Health Literacy: A programme evaluation of the teacher training education on the Mental Health \& High School Curriculum Guide. Advances in School Mental Health Promotion, 6(2), published online 29 April 2013 at http://www.tandfonline.com/doi/full/10.1080/1754730X. 2013.784615\#tabModule.

[11] Kutcher, S., \& Wei, Y. (2013). Challenges and solutions in the implementation of the school-based pathway to care model: the lessons from Nova Scotia and beyond. Canadian Journal of School Psychology, 28(1): 90-102.

[12] SBMHSA Consortium. (2013). School-based mental health in Canada: a final report. Mental Health Commission of Canada. Retrieved February 4, 2014 from http://www.mentalhealthcommission.ca/English/node/14 036 .

[13] Kutcher, S., \& McLuckie, A. (2010). For the Child and Youth Advisory Committee, Mental Health Commission of Canada. Evergreen: A child and youth mental health framework for Canada. Calgary, AB: Mental Health Commission of Canada. 
[14] Nova Scotia Department of Education (2012). Kids \& learning first: A plan to help every student succeed. Halifax, NS: Nova Scotia Department of Education.

[15] Skre, I, Friborg, O., Breivik, C., Johnsen, L., Arnesen, Y., and Wang, C. (2013). A school intervention for mental health literacy in adolescents: effects of nonrandomized cluster controlled trial. BMC Public Health, 13,873 .

[15] Jorm, AF, Blewitt, KA, Griffiths, KM., Kitchener, BA, Parslow, RA. (2005). Mental health first aid responses of the public: results from a Australian national survey. BMC Psychiatry, 5:9.

[16] Evans-Lacko, S., London, J., Japhet, S., Rüsch, N., Flach, C., Corker, E., Henderson, C., and Thornicroft, G. (2012). Mass social contact interventions and their effect on mental health related stigma and intended discrimination. BMC Public Health, 12; 489.

[17] McLuckie, A., Kutcher, S., Wei, Y., Weaver, C. (2014). Sustained Improvements in students' mental health literacy and attitudes towards mental illness with use of a mental health curriculum in Canadian schools. Unpublished manuscript.

[18] Milin, R., Kutcher, S., Lewis, S., Walker, S., Ferrill, N. (2013). Randomized controlled trial of a school-based mental health literacy intervention for youth: impact on knowledge, attitudes, and help-seeking efficacy. Poster presentation at the $60^{\text {th }}$ AACAP Annual meeting.

[19] TeenMentalHealth.Org (2013a). Mental Health \& High School Curriculum Guide: Training Report for Nova Scotia. Retrieved March 24, 2014 from http://teenmentalhealth.org/resources/entries/mentalhealth-high-school-curriculum-guide-training-report-fornova-scotia

[20] TeenMentalHealth.Org (2013a). Mental Health \& High School Curriculum Training: Report for Ontario. Retrieved March 24, 2014 from http://teenmentalhealth.org/resources/entries/mentalhealth-and-high-school-curriculum-guide-training-reportfor-ontario

[21] TeenMentalHealth.Org (2013a). Mental Health \& High School Curriculum Training: Report for Calgary. Retrieved March 24, 2014 from http://teenmentalhealth.org/resources/entries/mentalhealth-high-school-curriculum-guide-training-report-forthe-calgary

[22] Weare, K. \& Nind, M. (2011). Mental health promotion and problem prevention: what does the evidence say? Health Promotion International, (suppl 1): 29-69.

[23] Hamwaka K. (in press). 'A peer mental health educator model for African schools: Untapped potential', in Kutcher, Wei and Weist edits, International School Mental Health for Adolescents: Global Opportunities and Global Challenges. Cambridge University Press. 